\title{
A lingüística e a ciência da informação: estudos de uma interseção
}

\section{Ercilia Severina Mendonça}

Bibliotecária da Divisão de Processamento T écnico da Diretoria de Bibliotecas do D epartamento Geral de Cultura da Secretaria M unicipal de Cultura do Rio de Janeiro. A luna do Curso de Especialização em Formação de D ocentes U niversitários da Escola de Educação da Universidade do Rio de Janeiro - U nirio.

E-mail: erciliamendonca@ zipmail.com.br

\section{Resumo}

A temática da lingüística e da ciência da informação na atualidade reúne alguns dos principais problemas do campo da informação. A lingüística, utilizada para a construção de conceitos no campo do conhecimento humano, e a ciência da informação, responsável pelo tratamento e transmissão deste conhecimento. Partindo-se de uma pesquisa em artigos de periódicos científicos da área, este estudo destaca sete pontos em que ocorre a interseção lingüística e ciência da informação, na tentativa de analisar cada um dentro da perspectiva exposta. Os pontos destacados foram os seguintes: o teórico; o quantitativo, pela visão bibliométrica; o temático, pela representação da informação; o aplicativo, pelos métodos diversos; o ensino, pelas relações curriculares; o tecnológico, pela teoria de sistemas; e normativo, pelas classificações bibliográficas. Procurou-se, com esta linha, colocar de maneira objetiva os pontos que mais suscitam a preocupação dos teóricos em relação ao tema pesquisado. Uma das grandes problemáticas reveladas na pesquisa foi a construção de conceitos e a representação da informação. Esta constatação perpassa pela terminologia e pela análise documentária, que serão as áreas mais estudadas na década que se inicia.

\section{Palavras-chave}

Lingüística; Ciência da informação; Linguagem documentária.

\section{The linguistics and the science of information: studies of an intersection}

\begin{abstract}
The thematic of the linguistics and of the science of the information, at the present time it gathers some of the main problems of the field of the documentation and of the information. The linguistics, used for the construction of concepts in the field of the human knowledge and the science of the information, responsible for the treatment and the transmission of this knowledge. Breaking of the literature revision, in goods of scientific newspapers of the area, this research highlights seven points where it happens the intersection of the linguistics with the Science of the Information. The outstanding points were: the theoretical; the quantitative, the thematic, the application, the teaching, the technological, and the normative. One of the great problems revealed in the research went to construction of concepts and the representation of information. This verification perpassa for the terminology and of the analisys documentary that will be the field more research in the decade that going to begin.
\end{abstract}

\section{Keywords}

Linguistics; Science of the information; Documentary language.

\section{INT RO DU ÇÃ O}

0 desenvolvimento de pesquisas na área da ciência e tecnologia, a explosão informacional e a fragmentação do conhecimento impõem a necessidade de se tratar de maneira racional e analítica o conteúdo dos documentos, com o fim de obter uma melhor representação para uma recuperação eficaz da informação produzida. Este processo vem colocando em questão duas áreas distintas no seu fazer científico e ao mesmo tempo aplicativas e complementares: a lingüística, que, após a década de 60, com a revolução elaborada por N oam Chomsky, ganhou status de ciência transformacional e desde então vem constantemente sendo solicitada para a construção de conceitos em diversos campos do conhecimento humano, e a ciência da informação, que, gerada após a II Guerra Mundial, recebeu a incumbência de lidar com 0 tratamento e transmissão do conhecimento produzido, com a responsabilidade ainda de zelar pelo papel social da informação. Esta interface, inaugurada também na década de 60 , tem sido enriquecida com novas abordagens, mas está longe de resultados positivos.

A contribuição da lingüística, via linguagem, e a função social da ciência da informação, via comunicação, fornecem uma das questões prioritárias no meio documental neste final de século. Foucault diz que "a existência da linguagem é soberana, pois que as palavras receberam a tarefa e 0 poder de representar 0 pensamento"1 ${ }^{1}$. Pensamento representado pela extensão do vocabulário e pela fertilidade de seus elementos na qual se incluem dois modos operantes: o fixo, em que a palavra é a base da construção limitada, restrita, e o flexível, em que as palavrastêm múltiplas definiçõese são dotadas de combinações associativas, segundo $\mathrm{M}_{\text {oles }}$.

\footnotetext{
${ }^{1}$ FO U CA ULT, M ichel. A s palavras e as coisas. São Paulo : M artins Fontes, 1999. 541 p. p. 107.

${ }^{2}$ M O LES, A braham A ntoine. Sociodinâmica da cultura. São Paulo : Perspectiva, 1974. 336 p., p. 22
} 
A ciência da informação, que investiga as propriedades e comportamento da informação, as forças governantes dos fluxos e os meios de processar a informação, ten do como objetivo a sua organização, armazenamento, recuperação e disseminação, tem estreita ligação com a lingüística pela intermediação da análise documentária, que se utiliza de métodos e processos para descrever o conteúdo dos documentos. M uitos são os teóricos que colaboram com pesquisas para a interface lingüística e ciência da informação, estudando as subáreas desses campos, como a análise documentária e a lingüística aplicada, a documentação e a lingüística, procuran do subsídios para a aplicação dessas duas áreas. $0 \mathrm{~s}$ estudos mais recentes apontam para a tendência terminologia e análise documentária, subáreas mais estudadas nos últimos 10 anos pelos teóricos da informação e semanticistas. Estes estudos visam a buscar na próxima década o rigor para as práticas de construção de vocabulários para fins de documentação.

Pretendeu-se, dentro deste trabalho, colocar em pauta a questão da lingüística no âmbito da ciência da informação, verificando a importância isolada e conjunta dessas duas disciplinas, o grau de interação e comprometimento que cada uma assume diante das perspectivas do conhecimento humano.

A partir desses dados, julgamos ser esta pesquisa um aval importante para a adoção de disciplinas ligadas ao campo da lingüística, como a terminologia, nos currículos inerentes à formação de profissionais bibliotecários, documentalistas, que lidam com a área da ciência da informação, visto que, pelo apresentado, a lingüística abre todo um leque de questões no desenvolvimento da linguagem e da tecnologia, que estão cada vez mais presentes no campo documental.

\section{METODOLOGIA}

Para estabelecer as relações entre a lingüística e a ciência da informação, consideraram-se apenas os artigos que reunissem os dados temáticos em periódicos relevantes na área da ciência da informação. Primeiro, efetuou-se um amplo levantamento nos periódicos da área da informação para a coleta de material bibliográfico que tratasse do tema.

Foram analisados os seguintes periódicos:

- Revista de biblioteconomia e C omunicação da U niversidade F ederal do Rio G rande do Sul;
- Revista Brasileira de Biblioteconomia e D ocumentação de São Paulo;

- Revista da Escola deB iblioteconomia da U niversidadeF ederal de M inas $G$ erais;

- Revista Perspectiva em C iência da Informação da U FM G (substituiu a anterior);

- Revista de Biblioteconomia de Braślia;

- Revista Informare do Instituto Brasileiro de Informação Ciência e T ecnologia - IBICT.

- Revista C iência da Informação do IBICT.

0 critério utilizado para enquadrar os artigos dos periódicos dentro do tema foi a análise do título e do resumo, preocupando-se em detectar o termo lingüística. A pós esta análise, verificou-se que a revista Ciência da Informação do IBICT apresentou-se como o periódico que concentrava o maior número de artigos sobre o tema, sendo por esta razão escolhida para o referido estudo.

A C iência da Informação é uma publicação científica na qual são publicados os trabalhos dos profissionais e pesquisadores dessa área. Fundada em 1972, a Ciência da Informação, editava, até 1991, doisfascículosanualmente, passando em 1992 a editar trêsfascículos, que permanecem até hoje. N os anos de 1976 e 1980, foi editada apenas uma revista em cada um desses anos, reunindo os números 1 e 2 no mesmo volume anual. A C iência da Informação, como veículo impresso, ocupa papel fundamental na disseminação e na difusão do conhecimento, sen do o mais abrangente meio de comunicação técnico-científico nessa área, servindo como memória e enriquecimento cultural da sociedade como um todo.

Foram utilizados todos os volumes publicados desde 0 lançamento da revista em 1972 até o último fascículo de 1998. No levantamento propriamente dito, primeiramente foram arrolados todos os fascículos, fazendo-se cópia dos sumários da revista, para uma leitura e seleção dos artigos. A pós esta seleção, efetuou-se a cópia dos artigos para leitura e verificação dos termos lingüísticos, que tiveram como representantes: a semântica, que é o meio de representação do sentido dos enunciados ; a morfologia, que é o estudo das formas das palavras em oposição ao estudo das funções ou sintaxe; a fonética, que é o estudo do conjunto de possibilidades fônicas do homem através de todas as línguas naturais; a sintaxe, que é a parte da gramática que descreve as regras pelas quais se combinam as unidades significativas em 
frases $^{3}$. Desta fase resultou o quantitativo de 42 artigos, selecionados nos 27 volumes e 59 fascículos da revista. A pós identificar a presença dos termos lingüísticos e constatar a viabilidade da pesquisa, procedeu-se à seleção e divisão dos artigos dentro da temática da interseção criada entre a lingüística e as áreas reconhecidas dos estudos da informação. O bservou-se que os artigos nesta interface lingüística e ciência da informação estavam inseridos na grande área da organização do conhecimento e representação da formação, caracterizados pelos: fundamentos teóricos; sistemas de classificação e tesauros, estrutura e construção; classificação e indexação, métodos; representação do conhecimento por linguagem e terminologia; classificação e indexação aplicadas; sistemas de classificação universal e tesauros; ambiente da organização conhecimento. Dentro deste contexto, identificaram-se sete grupos principais, que são:

- teórico - abordagem textual;

- quantitativo - lingüístico e bibliométrico;

- temático - processamento intelectual, abordagem semântica, conceitual e terminológica;

- aplicativo - projetose modelos de indexação automática e linguagem natural;

- ensino - relações curriculares;

- tecnológico - sistemas especialistas e inteligência artificial;

- normativo - lingüística e classificação decimal universal.

Estes sete grupos temáticos foram analisados posteriormente com maior detalhamento, com o objetivo de identificar o conteúdo específico dos artigos neles contidos, para determinar os subgrupos temáticos. Os grupos possuem de um a quatro subgrupos que são apresentados de acordo com a subdivisão temática do assunto, incluindo a data, o título e a autoria do artigo, bem como o vínculo institucional do autor à época de publicação do artigo.
QUADRO 1

\section{Grupos temáticos e subgrupos}

\begin{tabular}{|c|c|}
\hline $\begin{array}{l}\text { GRUPOS } \\
\text { TEMÁTICOS }\end{array}$ & SUBGRUPOSTEMÁTICOS \\
\hline $\begin{array}{l}\text { 1. A bordagem } \\
\text { textual. (teórico) }\end{array}$ & $\begin{array}{l}\text { 1.1 A bordagem geral e profunda dos } \\
\text { aspectos da linguagem e da linguagem } \\
\text { documentária. } \\
\text { 1.2 A estruturação ea representação do } \\
\text { conhecimento através de elementos da } \\
\text { linguagem e da psicologia cognitiva. } \\
\text { 1.3 O s parâmetros das áreas da docu- } \\
\text { mentação e da pesquisa. } \\
\text { 1.4 A s novas disciplinas que interagem } \\
\text { no campo da ciência da informação. }\end{array}$ \\
\hline $\begin{array}{l}\text { 2. Lingüística e } \\
\text { Bibliometria. } \\
\text { (quantitativo) }\end{array}$ & $\begin{array}{l}2.1 \text { A validade da Lei de Zipf na } \\
\text { quantificação da informação. }\end{array}$ \\
\hline $\begin{array}{l}\text { 3. A representação } \\
\text { da informação, } \\
\text { abordagem } \\
\text { semântica, } \\
\text { conceitual e } \\
\text { terminológica. } \\
\text { (temático) }\end{array}$ & $\begin{array}{l}\text { 3.1 A tradução do termo descritor e a } \\
\text { temática do empréstimo lingüístico. } \\
\text { 3.2 Q uestões e contribuições filosóficas } \\
\text { na representação do conhecimento. } \\
\text { 3.3 A s relações e contribuições } \\
\text { lexicográficas. } \\
\text { 3.4 A estruturação de conceitos visando } \\
\text { à recuperação da informação. }\end{array}$ \\
\hline $\begin{array}{l}\text { 4. } 0 \text { estudo da } \\
\text { indexação } \\
\text { automática e da } \\
\text { linguagem } \\
\text { natural. } \\
\text { (aplicativo) }\end{array}$ & $\begin{array}{l}\text { 4.1 As abordagens da indexação auto- } \\
\text { mática que estudam a aplicação } \\
\text { operacional da estrutura de projetos. } \\
4.2 \text { A recuperação automática e o } \\
\text { processamento eletrônico da informa- } \\
\text { ção em base de dados. } \\
4.30 \text { uso do sintagma nominal no enca- } \\
\text { deamento da informação. }\end{array}$ \\
\hline $\begin{array}{l}\text { 5. A s relações } \\
\text { curriculares. } \\
\text { (ensino) }\end{array}$ & $\begin{array}{l}5.1 \text { A s relações curriculares da lingüísti- } \\
\text { ca com a biblioteconomia, a documen- } \\
\text { tação e a ciência da informação. }\end{array}$ \\
\hline $\begin{array}{l}\text { 6. A s tecnologias } \\
\text { dos sistemas } \\
\text { especialistas e a } \\
\text { inteligência } \\
\text { artificial. } \\
\text { (tecnológico) }\end{array}$ & $\begin{array}{l}6.1 \text { O s sistemas especialistas e a } \\
\text { temática da inteligência artificial para uso } \\
\text { na recuperação da informação. }\end{array}$ \\
\hline $\begin{array}{l}\text { 7. A classificação } \\
\text { decimal } \\
\text { universal e a } \\
\text { lingüística. } \\
\text { (normativo) }\end{array}$ & $\begin{array}{l}\text { 7.1 } 0 \text { atraso no desenvolvimento da } \\
\text { CDU em relação ao campo lingüístico. } \\
\text { 7.2 A ausência de normalização e o uso } \\
\text { dalinguagem nas tabelas de classificação. }\end{array}$ \\
\hline
\end{tabular}




\section{A LING ÜÍSTICA NA CIÊNCIA DA IN FORMAÇÃ O: CONSIDERAÇÕES GERAIS}

Todas as ciências são estruturadas perante 0 desenvolvimento da humanidade, mas nem todas têm uma implicação tão forte, tão dependente desse processo quanto a Lingüistica, podendo-se dizer que interfere nos outros meios de desenvolvimento humano, como a antropologia, a sociologia, a filosofia ou a economia, pelo simples fato de ter como objeto de estudo a linguagem oral, escrita e representada, como um elo de fundamental importância nesse desenvolvimento. Reportamo-nos novamente a Foucault quando diz que:

"O que distingue a linguagem de todos os outros signose Ihe permite desempenhar na representação um papel decisivo não éo fato de ser individual ou coletiva, natural ou artificial, mas sim o fato de que ela analisa a representação segundo uma ordem necessariamente sucessiva (...), a linguagem não pode representar 0 pensamento de imediato, na sua totalidade ; precisa dispôlo parte por parte segundo uma ordem linear. (...) É nesse sentido estrito que a linguagem é análise do pensamento: não simples repartição, mas instauração profunda da ordem no espaço"4.

A área da documentação, de modo geral, envolve segmentos que estão inseridos nas partes que formam 0 todo, de modo que a divisão temática dos artigos possibilitou melhor análise do seu conteúdo. Estasanálises foram feitas com vistas ao reconhecimento dos aportes teóricos da lingüística. Em cada grupo temático procedeuse a descrever de que maneira foi estabelecida a relação entre a lingüística e a ciência da informação.

N os 27 anos de publicação da revista C iência da Informação foram editados 59 fascículos, apenas em 26 desses fascículos foram publicados artigos com o tema lingüística e ciência da informação, ou seja, quase a média de um artigo por ano de publicação sobre o tema.

$\mathrm{N}$ a década de 70, produziram-se nove artigos, sendo três no ano de 1977, nos quais a ênfase está toda voltada para o termo conceito; 1973 e 1974 tiveram como assunto principal a bibliometria, ou seja, na década de 70 priorizaram-se a estruturação de conceitos e a quantificação do conhecimento/informação. N os anos de 1972, 1976 e 1979, não foram encontrados artigos sobre 0 tema. A década de 80 , a mais produtiva em termos anuais, trouxe a representação do conhecimento como tema principal. O s anos de 1983 e 1986, voltaram-se para as
QUADRO 2

Edições da revista C iência da Informação Período 1972 a 1998

\begin{tabular}{|c|c|c|}
\hline A no & Vol. & $\mathrm{N}$ úmero \\
\hline 1972 & 1 & 1 e 2 \\
\hline 1973 & 2 & 1 e 2 \\
\hline 1974 & 3 & 1 e 2 \\
\hline 1975 & 4 & 1 e 2 \\
\hline 1976 & 5 & $1 / 2$ \\
\hline 1977 & 6 & 1 e 2 \\
\hline 1978 & 7 & 1 e 2 \\
\hline 1979 & 8 & 1 e 2 \\
\hline 1980 & 9 & $1 / 2$ \\
\hline 1981 & 10 & 1 e 2 \\
\hline 1982 & 11 & 1 e 2 \\
\hline 1983 & 12 & 1 e 2 \\
\hline 1984 & 13 & 1 e 2 \\
\hline 1985 & 14 & 1 e 2 \\
\hline 1986 & 15 & 1 e 2 \\
\hline 1987 & 16 & 1 e 2 \\
\hline 1988 & 17 & 1 e 2 \\
\hline 1989 & 18 & 1 e 2 \\
\hline 1990 & 19 & 1 e 2 \\
\hline 1991 & 20 & 1 e 2 \\
\hline 1992 & 21 & 1,2 e 3 \\
\hline 1993 & 22 & 1,2 e 3 \\
\hline 1994 & 23 & 1,2 e 3 \\
\hline 1995 & 24 & 1,2 e 3 \\
\hline 1996 & 25 & 1,2 e 3 \\
\hline 1997 & 26 & 1,2 e 3 \\
\hline 1998 & 27 & 1,2 e 3 \\
\hline
\end{tabular}

${ }^{4}$ FO U CA U LT, op. cit., p. 113-114. 
políticas de indexação. N os anos de 1980 e 1981, não foram encontrados artigos sobre o tema. Já na década de 90, publicaram-se 19 artigos, com uma maior produção no ano de 1995, no qual foi abordada amplamente a questão lingüística, via léxico e terminologia. No ano de 1996, publicaram-se quatro artigos que discutiam a questão da representação, via ciência da informação. D entro desta análise de dados, podemos concluir que a década de 90 , independentemente do aumento de fascículos da revista, foi a que mais abordou e produziu sobre o tema lingüística e ciência da informação. N os anos de 1990, 1994 e 1998, não foram encontrados artigos sobre o tema. 0 crescimento exponencial de produção científica entre as décadas foi igual, em uma média de cinco artigos.

T odos os assuntos tiveram a média de um autor para cada artigo, sendo que a terminologia e a representação do conhecimento apresentaram dois autores que publicaram mais de um artigo ( A nexo 1). O s assuntos mais discutidos nesta interface foram terminologia, indexação automática, ciência da informação, bibliometria, biblioteconomia, linguagem documentária, base de dados e sistemas especialistas ( $A$ nexo 2). Esta tendência terminológica e tecnológica reflete a preocupação dos teóricos da ciência da informação com a abordagem lingüística.

\section{GRUPO 1: ABORDAGEM TEXTUAL}

O sartigos enquadrados neste primeiro grupo da pesquisa tratam da relação teórica entre a lingüística e a ciência da informação. São estudos desenvolvidos com o intuito de descrever ou aprofundar a compreensão dessa interface. Foram selecionadosneste grupo nove artigos que abordam as problemáticas da área documental, tais como o acesso à informação, a estruturação e a representação do conhecimento e o uso da informação. Esta parte teórica está fundamentada nos estudos produzidos nos artigos, que foram divididos em quatro subgrupos.

\section{SUBGRUPOS}

1.1- A bordagem geral e profunda dos aspectos da linguagem e da linguagem documentária.

1.2- A estruturação e a representação do conhecimento por meio de elementos da linguagem e da psicologia cognitiva.

1.3- O s parâmetros das áreas da documentação e da pesquisa.

1.4- A s novas disciplinas que interagem no campo da ciência da informação.
QUADRO 3

A rtigos coletados e selecionados por década/ano dentro do tema da pesquisa

\begin{tabular}{cccccc}
\hline \multicolumn{6}{c}{ A NOS E N ÚMEROS DE } \\
\hline 1972 & - & 1980 & - & 1990 & - \\
1973 & 2 & 1981 & - & 1991 & 2 \\
1974 & 2 & 1982 & 1 & 1992 & 1 \\
1975 & 1 & 1983 & 3 & 1993 & 2 \\
1976 & - & 1984 & 1 & 1994 & - \\
1977 & 3 & 1985 & 1 & 1995 & 8 \\
1978 & 1 & 1986 & 3 & 1996 & 4 \\
1979 & - & 1987 & 2 & 1997 & 2 \\
TOTAL & 9 & 1988 & 1 & 1998 & - \\
& & 1989 & 2 & TOTAL & 19 \\
\hline
\end{tabular}

ENFOQUE SUBGRUPO 1.1 A bordagem geral e profunda dos aspectos da linguagem
e da linguagem documentária

\begin{tabular}{llll}
\hline DATA & TÍTULO & A UTOR & IN ST ITUIÇÃ O \\
\hline 1973 & $\begin{array}{l}\text { Linguagem } \\
\text { documentária, acesso } \\
\text { à informação: aspectos } \\
\text { do problema. }\end{array}$ & $\begin{array}{l}\text { M anoel } \\
\text { W dolpho }\end{array}$ & BN/FEFIEG \\
& & \\
\hline
\end{tabular}

Fruto de uma dissertação, este artigo aborda as relações entre a linguagem e 0 universo da representação formal, objeto da linguagem documentária. É interessante no âmbito desta pesquisa destacar um trecho da introdução dessa dissertação, em que 0 autor também se pergunta sobre as condições lingüísticas na ciência da informação.

“Então não estaríamos estado, nós, bibliotecários e documentaristas, a fazer lingüistica sem o saber - quase diríamos sem a saber? - a criar linguagens que desejamos tão significativas quanto a natural? a traduzirmos em códigos os textos em nossa custódia? a frasear-Ihes 0 conteúdo em resumos sinaléticos ou informativos, produzindo documentos derivados que dão acesso aos primários, numa palavra, ao comunicarmos ao leitor mensagensque no intuíto de lhe responderem asquestões, os autores confiaram ao nosso zelo e guarda?" 5

\footnotetext{
${ }^{5}$ W A N DERLEY, M anoel A dolpho. Linguagem documentária, acesso à informação : aspectos do problema.

Ciência da Informação, Rio de Janeiro, v. 2, n. 2, p. 175-217, 1973. p. 175.
} 
0 texto bastanteamplo no sentido deabordagens, discorre sobre várias vertentes, modelos, teorias, idéiase resoluções em que habitam essas interfaces. A nalisa a lingüística e suas implicações : fonemas, morfemas, sintagmas. A nalisa a semântica, a gramática, a lógica e os domínios da linguagem documentária e seus referentes. $\mathrm{N}$ a verdade, $\mathrm{O}$ subtítulo "acesso à informação" abre um grande leque de parâmetros que envolvem a linguagem documentária, tendo-se por este motivo uma abordagem teórica múltipla, que em parte engl oba todas as outras temáticas dosartigos analisados nesta pesquisa.

\section{ENFOQUE SUBGRUPO 1.2}

\section{A estruturação e a representação do conhecimento por meio de elementos da linguagem e da psicologia cognitiva}

\begin{tabular}{|c|c|c|c|}
\hline DATA & TÍTULO & AUTOR & IN ST ITUIÇÃ O \\
\hline 1977 & $\begin{array}{l}\text { A organização de } \\
\text { conceitos para } \\
\text { recuperação da } \\
\text { informação }\end{array}$ & $\begin{array}{l}\text { Suman } \\
\text { Datta }\end{array}$ & $\begin{array}{l}\text { Tradução M aria de } \\
\text { Lurdes C. Pierotti } \\
\text { (CN Pq) e H elena M. P. } \\
\text { Braga (IBICT). }\end{array}$ \\
\hline 1978 & Teoria do conceito & $\begin{array}{l}\text { Ingetraut } \\
\text { Dalhberg }\end{array}$ & $\begin{array}{l}\text { Universidade de } \\
\text { Brasillia. T radução: } \\
\text { A stério T. Campos. }\end{array}$ \\
\hline 1984 & $\begin{array}{l}\text { Informação e } \\
\text { conhecimento }\end{array}$ & $\begin{array}{l}\text { M aria } \\
\text { N élida G. } \\
\text { de Gomes }\end{array}$ & IBICT/UFRJ \\
\hline
\end{tabular}

0 s artigos deste subgrupo enfocam o conceito visto pelo prisma do conhecimento e recuperação da informação. 0 primeiro artigo apresenta a exposição e análise de sistemas de relações semânticas desenvolvidas por Farradane e Guilford, os mecanismosmentais e a origem dos conceitos básicos e os seus níveis de complexidade. São vários os tipos de organização de conceitos.

Coloca também a inter-relação semântica e a psicologia do pensamento na formação de conceitos, visando a uma maior estruturação do conhecimento para maior flexibilidade de uso de termos da classificação geral. Já D ahlberg enfoca toda uma referência do termo conceito, por meio de tipologias, funções, relações e extensão de conceitos. A formação de conceitos pode ser definida segundo Dahlberg como:

"A reunião e compilação de enunciados verdadeiros a respeito de determinado objeto. Para fixar o resultado dessa compilação necessitamos de um instrumento. Este instrumento é constituído pela palavra ou por qualquer signo que possa traduzir efixar essa compilação. É possível definir, então, o conceito como a compilação de enunciados verdadeiros sobre determinado objeto, fixado por um símbolo lingüístico"6.

0 terceiro artigo coloca o usuário da informação como 0 sujeito do conhecimento, baseado nas premissas cognitivas que transformam os processos do saber. T odos esses artigos se utilizam da linguagem e da lingüística como um sistema de relações para estabelecer normas na organização de conceitos.

\section{ENFOQUE SUBGRUPO 1.3}

\section{O s parâmetros das áreas da documentação e da pesquisa}

\begin{tabular}{llll}
\hline DATA & TÍTULO & AUTOR & IN STITUIÇÃ O \\
\hline 1987 & $\begin{array}{l}\text { Ciência da } \\
\text { Informação e } \\
\text { prática bibliotecária }\end{array}$ & $\begin{array}{l}\text { Edson Nery } \\
\text { da Fonseca }\end{array}$ & $\begin{array}{l}\text { Universidade de } \\
\text { Braślia }\end{array}$ \\
1996 & $\begin{array}{l}\text { Ciência da } \\
\text { Informação: uma } \\
\text { ciência, uma } \\
\text { revista }\end{array}$ & $\begin{array}{l}\text { Solange } \\
\text { Puntel }\end{array}$ & $\begin{array}{l}\text { Universidade } \\
\text { Católica de }\end{array}$ \\
& & Campinas \\
\end{tabular}

Este subgrupo, representado por dois artigos, apresenta dois autores que retomam e discutem o conteúdo histórico e teórico da área da informação e da comunicação. Fonseca relata, na tentativa de esclarecer a interdepen dência entre a biblioteconomia, a documentação e a ciência da informação, os fatos relevantes de cada uma dessas áreas, apresentando como delimitadores de fronteiras os seus campos de interseção. 0 autor contraria a zona de conflito denominada por outros autores e faz uma descrição histórica das áreas da informação, passando pela interdisciplinaridade. A lingüística encontra-se posicionada na área da documentação e da ciência da informação como uma ciência conexa. M ostafa, em seu artigo de teor filosófico, aborda a busca de conhecimento no âmbito da realidade contraditória, identificando as áreas de concentração e contradição dasnovas disciplinas como uma nova forma para novas ciências e novas revistas. A nalisa o contexto da ciência da informação enquanto ciência e disciplina, comparando-a à lingüística, que também remodela seus espaços de conhecimento, gerando novas disciplinas no intuito de se encontrar dentro destes recortes. Coloca a linguagem como uma área fundamental para a ciência da informação e que é pouco desenvolvida pela biblioteconomia, pelo fato de exigir aprofundamento no campo lingüístico.

${ }^{6}$ DAH LBERG, Ingetraut. T eoria do conceito. C iência da Informação, Rio de Janeiro, v. 7, n. 2, p. 101-107, 1978. p. 102. 
ENFOQUE SUBGRUPO 1.4

A s novas disciplinas que interagem no campo da ciência da informação.

\begin{tabular}{|c|c|c|c|}
\hline DATA & TÍTULO & AUTOR & IN ST ITUIÇÃ O \\
\hline 1995 & $\begin{array}{l}\text { Socioterminologia: } \\
\text { mais que um } \\
\text { instrumento de } \\
\text { pesquisa, uma disciplina }\end{array}$ & $\begin{array}{l}\text { Enilde } \\
\text { Faulstich }\end{array}$ & $\begin{array}{l}\text { Universidade de } \\
\text { Brasília }\end{array}$ \\
\hline 1995 & $\begin{array}{l}\text { Terminologia do ensino } \\
\text { por computador: } \\
\text { abordagem } \\
\text { socioterminológica }\end{array}$ & $\begin{array}{l}\text { A na Sofia } \\
\text { Brito e } \\
\text { Rosa dos } \\
\text { A njos Olive }\end{array}$ & $\begin{array}{l}\text { Universidade de } \\
\text { Brasília }\end{array}$ \\
\hline 1995 & $\begin{array}{l}\text { Terminologia: o projeto } \\
\text { Brasilterm e a formação } \\
\text { de recursos humanos }\end{array}$ & $\begin{array}{l}\text { Enilde } \\
\text { Faulstich }\end{array}$ & $\begin{array}{l}\text { Universidade de } \\
\text { Brasília }\end{array}$ \\
\hline
\end{tabular}

Estes três artigos, datados de 1995 e publicados no mesmo fascículo da revista, abordam o contexto de duas disciplinas: a terminologia e a socioterminologia. A terminologia moderna, fundada por Eugen W üster em 1931, ganha em 1981 um novo desdobramento da sua metodologia através da disciplina denominada por JeanClaude Boulanger como socioterminologia. Faulstich, que estuda este assunto no Brasil, contribui com dois desses artigos: o primeiro apresenta a sobreposição da socioterminologia à terminologia. A autora ressalta que esta última disciplina não possui ainda estudos teóricos definidos e já ganha uma releitura da sua metodologia. Faulstich define a socioterminologia como prática de trabal ho terminológico que se fundamenta na análise do termo e como disciplina descritiva que estuda o termo sob perspectiva lingüística. Coloca ainda os dois princípios que auxiliam a pesquisa socioterminológica, como a sociolingüística e a etnografia. Em seu segundo artigo, Faulstich destaca a formação de grupos de pesquisa e de profissionais em terminologia pelo Projeto Brasilterm, que tem como finalidade a implantação e a difusão da terminologia científica e técnica no Brasil e nos países da A mérica Latina, visando também ao $M$ ercosul. Dentro desse conteúdo terminológico, Peixoto e O liveira abordam a metodologia de ensino por computador, com o objetivo de preparar instrumentos para a coleta de dados antes da elaboração de glossário de termos relativos a este ensino, e enfatizam a necessidade de um consenso terminológico, tendo em vista as mudanças no quadro educacional do país. Destacam a elaboração e avaliação de softwares educacionais, o ensino de informática elinguagem própria, além da formação de profissionais para atuar na área.

\section{GRUPO 2: LINGÜÍSTICA E BIBLIOMETRIA}

O sartigos enquadradosneste grupo dois da pesquisa tratam das questões estatísticas relacionadas ao campo de interseção entre a lingüística e a bibliometria. Foram selecionados neste grupo apenas dois artigos que abordam a quantificação da informação mediante procedimentos das leis bibliométricas. A ciência da informação, como área abrangente da pesquisa, tem na bibliometria, campo da biblioteconomia, a sua área de estudos quantitativos, pois a bibliometria indica o tratamento quantitativo da comunicação escrita através de várias aplicações, sendo a freqüência das palavras no texto o método mais utilizado. Estabelecida em 1916 por J. B. Estoup e popularizada por G. K. Zipf em 1949, que, segundo M aia, "formulou leis estabelecendo relações entre a ordem de série de uma palavra em ordem de freqüência e a freqüência de seu aparecimento em um texto suficientemente longo" 7 . Esta primeira lei de Zipf foi baseada na relação empírica observada por Estoup. A segunda lei de Zipf, que se refere às palavras de baixa freqüência, ainda não foi suficientemente estudada para ser aplicada à língua portuguesa. Pela ausência significativa de artigos que tratam deste assunto, em nosso campo empírico, este grupo se restringe a um só subgrupo, que de maneira geral verifica a validade das leis de Zipf para a língua portuguesa.

\section{SUBGRUPO}

2.1 - A validade da Lei de Zipf na quantificação da informação.

\section{ENFOQUE SUBGRUPO 2.1}

A validade da lei de Zipf na quantificação da informação

\begin{tabular}{llll}
\hline DATA & TÍTULO & AUTOR & INSTITUIÇÃ O \\
\hline 1973 & $\begin{array}{l}\text { Comportamento } \\
\text { bibliométrico da língua } \\
\text { portuguesa, como veículo } \\
\text { de representação da } \\
\text { informação }\end{array}$ & $\begin{array}{l}\text { Elza Lima } \\
\text { e Silva }\end{array}$ & IBICT \\
1974 & $\begin{array}{l}\text { A plicação dos métodos } \\
\text { estatísticose da teoria da } \\
\text { informação e da } \\
\text { comunicação na análise }\end{array}$ & Libeiro & \\
& IBICT & \\
& lingüística: estudo da & & \\
linguagem jornalística & & \\
\hline
\end{tabular}

${ }^{7}$ MAIA, Elza Lima e Silva. Comportamento bibliométrico na língua portuguesa, como veículo de representação da informação. Ciência da Informação, Rio de Janeiro, v. 2, n. 2, p. 99-138. 1973. p. 99. 
A mbos os artigos analisam a validade da lei de Zipf para a língua portuguesa, sendo que o primeiro se atém à quantificação da comunicação escrita como um todo e 0 segundo priorisa os métodos estatísticos da análise lingüística via computador. A segunda lei de Zipf, complementada pela fórmula de transição de Goffman, poderá também ser utilizada para a língua portuguesa, conforme estudos apresentados no primeiro artigo deste subgrupo. 0 s referenciais teóricos dos artigos são 0 tratamento quantitativo da informação escrita, a freqüência das palavras no texto, as relações entre ordem de série de palavras, palavras de baixa freqüência, uso de fórmula de transição, princípio do menor esforço, palavras de alta freqüência no texto e métodos de análise lingüística. Dentro da análise lingüística, foram examinados os níveis sintático, semântico e fonológico das palavras analisadas no texto.

É importante observar que 0 artigo de Ribeiro traz um contexto histórico da época, uma vez que analisa um veículo de informação popular em um período de 15 anos dentro da ótica editorial jornalística. Escrito na década de 70 , este artigo aborda a contribuição das técnicas computacionais na lingüística. Ribeiro acrescenta que a representação da informação tem como principal veículo a linguagem, sendo por isto obrigatória a interface ciência da informação elingüística. A primeira estuda os aspectos da comunicação, a segunda estuda a linguagem para a comunicação.

\section{GRUPO 3: A REPRESENTAÇÃO DA IN FORMAÇÃ O, ABORDAGEM SEMÂNTICA, CONCEIT UAL E TERMINOLÓGICA}

O sartigos en quadradosneste grupo três da pesquisa tratam dos textos e dos documentos resultantes da área da organização do conhecimento. 0 s 11 artigos selecionados neste grupo abordam a temática da representação do conhecimento com diversas acepções. 0 objetivo da ciência da informação é estudar o tratamento e a transmissão da informação mediante procedimentos metodológicos de caráter científico. A contribuição da lingüística neste contexto é fornecer subsídios que auxiliem os outros campos do conhecimento na construção de conceitos e parâmetros que definirão a sua própria estrutura científica. $V$ isando à amplitude de representações deste grupo, os artigos foram divididos em quatro subgrupos para análise.

\section{SUBGRUPOS}

3.1- A tradução do termo descritor e a temática do empréstimo lingüístico

3.2- Q uestões e contribuiçõesfilosóficas na representação do conhecimento

\section{3- A s relações e estruturações lexicográficas}

3.4- A estruturação de conceitos visando à recuperação da informação

\section{ENFOQUE SUBGRUPO 3.1}

\section{A tradução do termo descritor e a temática do empréstimo lingüístico}

\begin{tabular}{|c|c|c|c|}
\hline DATA & TÍTulO & AUTOR & IN ST ITUIÇÃ O \\
\hline 1986 & $\begin{array}{l}\text { Tradução e adaptação de } \\
\text { tesauros }\end{array}$ & $\begin{array}{l}\mathrm{H} \text { aruka } \\
\mathrm{N} \text { akayama }\end{array}$ & $\begin{array}{l}\text { Universidade de } \\
\text { Brasillia }\end{array}$ \\
\hline 1986 & $\begin{array}{l}\text { Tecnologia brasileira em } \\
\text { ciência da informação: } \\
\text { uma análise }\end{array}$ & $\begin{array}{l}\text { M arisa B. } \\
\text { Basílio } \\
\text { M edeiros }\end{array}$ & IBICT /Brasília \\
\hline 1989 & $\begin{array}{l}\text { Terminologia de } \\
\text { informática em língua } \\
\text { portuguesa: uma análise } \\
\text { língüística e terminológica }\end{array}$ & $\begin{array}{l}\text { Lígia M aria } \\
\text { C. de } \\
\text { M iranda }\end{array}$ & IBICT /Braślia \\
\hline
\end{tabular}

1995
Empréstimos nas línguas
de especialidade:

algumas considerações

Ieda Maria Universidade de Alves São Paulo

Estes artigos enfocam a tradução do termo descritor pelo processo lingüístico e terminológico, bem como as relações que qualificam o conceito. A bordam-se amplamente os problemas de tradução e a temática da equivalência entre a língua fonte e a língua alvo; assim, os termos sinonímia, homonímia, polissemia, cognatos, neologismos, empréstimos lingüísticose ambigüidade fazem parte desse referencial teórico. A lingüística, a semântica e as regras gramaticais são consideradas como peças fundamentais no processo de tratamento, normalização, tradução, construção e disseminação da informação através dos descritores. A tradução do termo descritor e a problemática do empréstimo lingüístico são dois dos grandes desafios da era documental, pois prima-se por um termo que represente, de maneira clara e objetiva, a informação por meio da normalização e padronização dos empréstimos lingüísticos que atualmente assolam a terminologia brasileira. 0 artigo de $\mathrm{N}$ akayama utiliza-se da área da lingüística no processo de construção de descritores, em que descreve as classes gramaticais que 
servem como base para formar os termos. Esta problemática de uso da lingüística na formação de descritores abrange várias áreas do conhecimento humano, especificamente dentro da área informacional, tais como a terminologia, a tradutologia e, mais recentemente, a socioterminologia - uma hiperespecialização da terminologia. T anto Nakayama quanto M edeiros, A lves e Miranda abordam este tema de padronização e, embora sob enfoques diferentes, concorrem para o mesmo resultado. 0 s autores colocam propostas de normalização e esbarram em obstáculos inerentes a estes procedimentos, tais como a sinonímia, a homonímia, a polissemia, os cognatos, os neologismos, a ambigüidade e a equivalência entre a língua fonte e a língua alvo nos empréstimos lingüísticos. 0 s artigos apontam também para as dificuldades em relação ao prestígio da língua detentora de tecnologia que impõe barreira à normalização brasileira. C omo diz M iranda: "A terminologia de informática em língua inglesa parece estar influenciando diferentemente as terminologias brasileira e portuguesa" ${ }^{8}$. C ruz, em artigo do grupo quatro, analisará o impacto desta influência em Portugal. 0 surgimento de conceitos novos essencialmente de origem inglesa tem na lingüística e na semântica as peças fundamentais para tratar estes fatores extralingüísticos a caminho da normalização brasileira.

\section{ENFOQUE SUBGRUPO 3.2}

\section{Q uestões e contribuições filosóficas na representação do conhecimento}

\begin{tabular}{|c|c|c|c|}
\hline DATA & TÍTULO & AUTOR & IN STITUIÇÃ O \\
\hline 1993 & $\begin{array}{l}\text { A representação do } \\
\text { conhecimento e o } \\
\text { conhecimento da } \\
\text { representação: algumas } \\
\text { questões epistemológicas }\end{array}$ & $\begin{array}{l}\text { M aria } \\
\text { N élida G. } \\
\text { de Gomes }\end{array}$ & IBICT/UFRJ \\
\hline 1993 & $\begin{array}{l}\text { A lgumas contribuições } \\
\text { da semiologia e da } \\
\text { semiótica para a análise } \\
\text { das linguagens } \\
\text { documentárias }\end{array}$ & $\begin{array}{l}\text { M arilda } \\
\text { Lopes G. } \\
\text { de Lara }\end{array}$ & $\begin{array}{l}\text { Universidade de } \\
\text { São Paulo }\end{array}$ \\
\hline
\end{tabular}

\footnotetext{
${ }^{8}$ M IRA NDA, Ligia M aria Café de. Terminologia de informática em língua portuguesa: uma análise lingüística e terminológica. Ciência da Informação, Brasília, v. 18, n. 2, p. 183-190, jul./dez. 1989. p. 183.
}

Os dois únicos artigos deste subgrupo apresentam as questões e as contribuições filosóficas na temática da representação do conhecimento, abordando a representação da informação sem comprometimento de significado. N estes dois artigos, o foco principal é a contribuição da filosofia da linguagem e da semiótica na representação dos signos documentários da informação controlada. A transferência da informação nos contextos social e técnico pelos processos culturais através de suportes que viabilizem a sua acessibilidade e comunicação. N este campo, discute-se o valor do signo dentro das temáticasfilosófica e lingüística como elemento de linguagem documentária.

\section{ENFOQUE SUBGRUPO 3.3}

\section{As relações e contribuições lexicográficas}

\begin{tabular}{|c|c|c|c|}
\hline DATA & TÍTULO & AUTOR & IN STITUIÇÃ O \\
\hline 1983 & $\begin{array}{l}\text { Elementos de lingüística } \\
\text { para estudos de indexação }\end{array}$ & $\begin{array}{l}\text { A nna } \\
\text { M aria M. } \\
\text { Cintra }\end{array}$ & IBICT \\
\hline 1995 & $\begin{array}{l}\text { O léxico na economia } \\
\text { da língua }\end{array}$ & $\begin{array}{l}\text { Margarita } \\
\text { Correia }\end{array}$ & $\begin{array}{l}\text { Universidade de } \\
\text { Lisboa }\end{array}$ \\
\hline 1995 & $\begin{array}{l}\text { Contribuição ao estudo } \\
\text { aspectos da tipologia de } \\
\text { obras lexicográficas }\end{array}$ & $\begin{array}{l}\text { M aria } \\
\text { A parecida } \\
\text { Barbosa }\end{array}$ & $\begin{array}{l}\text { Universidade de } \\
\text { São Paulo }\end{array}$ \\
\hline
\end{tabular}

Estes três artigos abordam as relações morfológicas do léxico na construção do vocabulário especializado, técnico e científico e sustentam a eliminação da informação redundante com base no princípio da economia. Tal princípio representa dois aspectos: o limite de termos e de regras de uma linguagem e a simplificação pela eliminação de termo redundante. Tais características constituem o princípio do menor esforço, que, segundo Correia, "é a eliminação de toda e qualquer informação que possa ser tida como redundante" ${ }^{\prime}$. Estes artigos tratam das estruturas lingüísticas propriamente ditas, porque discutem o léxico, o vocabulário, a palavra, o signo, a língua e toda a gama de termos que envolvem essas relações. $\mathrm{N}$ a formação de conceitos e na adoção das linguagens documentárias, éimprescindível a construção do vocabulário como meio de normal ização e recuperação da informação. Por outro lado, discute-se também a polissemia das palavras, como coloca Correia, já que "uma mesma palavra é capaz de denotar entidades

\footnotetext{
${ }^{9}$ CORREIA, Margarita. O léxico na economia da língua. Ciência da Informação, Braślia, v. 24, n. 3, p. 299-307, set./dez. 1995. p. 299.
} 
completamente distintas"10. Não existe uma relação unívoca entre uma forma significante e um conceito, esta mesma forma está relacionada com vários conceitos. Este fato remete ao conceito da metáfora derivada das acepções propostas pelos dicionários e à sinédoque. D entro dessas extensões de significados, aborda-se também a importância da área lexicográfica como fator de aprimoramento do saber, porque se admite a necessidade de um vocabulário técnico científico como um importante instrumento de pesquisa e sustentação do arcabouço teórico. N esta discussão, estão incluídos os tesauros, mais especificamente os dicionários e os glossários.

\section{ENFOQUE SUBGRUPO 3.4}

\section{A estruturação de conceitos visando à recuperação da informação}

\begin{tabular}{|c|c|c|c|}
\hline DATA & TÍTUlo & AUTOR & INSTITUIÇÃ O \\
\hline 1977 & $\begin{array}{l}\text { O conceito de relevância } \\
\text { e suas implicações }\end{array}$ & $\begin{array}{l}\text { Laura M. de } \\
\text { de Figueiredo }\end{array}$ & IBICT/UFRJ \\
\hline 1996 & $\begin{array}{l}\text { Perspectivas para o } \\
\text { estudo da área de } \\
\text { representação da } \\
\text { informação }\end{array}$ & $\begin{array}{l}\text { Maria Luiza } \\
\text { de A. } \\
\text { Campos }\end{array}$ & $\begin{array}{l}\text { U niversidade } \\
\text { Federal } \\
\text { Fluminense }\end{array}$ \\
\hline
\end{tabular}

O s artigos deste subgrupo abordam o conceito de relevância na análise da comunicação científica e a medida de produção da informação relacionada à representação. 0 artigo sobre relevância, pioneiro e único no tema na área documental brasileira, coloca o sistema de medida de produção da informação relacionada à estrutura do conhecimento e sua representação. 0 conceito de relevância na análise da comunicação está intrinsecamente ligado às leis da bibliometria, pois apareceu dentro do contexto de medida de uma fonte de informação e apresenta uma conotação probabilística, como consta do artigo de Figueiredo. Surgido no ano de 1950, na área da recuperação da informação, o conceito de relevância é estudado por cientistas da informação e semanticistas. Segundo estes últimos, "a informação com conteúdo significativo é equivalente à informação relevante"11. A autora ainda explica que "a ciência da informação tem tentado enten der e explicar o fenômeno relevância através de diversas abordagens, mas ainda

${ }^{10}$ CORREIA, op. cit., p. 304, nota 9.

11 FIGUEIRED 0, Laura Maia de. 0 conceito de relevância e suas implicações. Ciência da Informação, Rio de Janeiro, v. 6, n. 2. p. 75-78, 1977. p. $75,77$. existem várias falhas, como as que se relacionam com valores humanos envolvidos na comunicação do conhecimento"12. Conclui dizendo que o conceito de relevância não pode ser estudado como um fenômeno isolado, pois depende de diversos fatores neste processo de comunicação.

\section{GRUPO 4: 0 EST UDO DA IN DEXAÇÃO AUTOMÁTICA E DA LINGUAGEM NATURAL}

O s nove artigos enquadrados neste grupo quatro da pesquisa tratam dos assuntos indexação automática e linguagem natural na área da automação e recuperação de documentos em diferentes aspectos, como mostram as divisões dos subgrupos. A finalidade deste grupo é apresentar a análise e aval iação dos sistemas de indexação mediados pelo uso do computador e que se pautam na lingüística como área de apoio à sua evolução. Os documentosna linguagem de indexação são tratados pela anál ise de conteúdo, que consiste na ordenação, separação e classificação desses documentos. Segundo Robredo, a condensação da informação nos documentose a indexação são tão antigas quanto as bibliotecas, porém estas partes não foram devidamente estudadas e estruturadas como os outros procedimentos da documentação ${ }^{13}$. A tualmente, a indexação é um dos campos mais estudados pelos especialistas e constitui uma parte de fundamental importância dentro da ciência da informação, pelo avanço tecnológico e o emprego da inteligência artificial na recuperação da informação. D eacordo com o histórico de evolução da área de indexação e as abordagens feitas dentro dos artigos, dividiu-se este grupo em três subgrupos para fins de análise.

\section{SUBGRUPOS}

4.1 - A sabordagens da indexação automática que estudam a aplicação operacional da estrutura de projetos.

4.2 - A recuperação automática e o processamento eletrônico da informação em base de dados.

4.3 - 0 uso do sintagma nominal no encadeamento da informação.

${ }^{12}$ FIGUEIREDO, op. cit., p. 75, nota 11.

${ }^{13}$ RO BRED O . Jaime. D ocumentação de hoje e de amanhã : uma abordagem informatizada da blioteconomia e dos sistemas de informação. São Paulo : Global, 1994. 400 p. p. 201. 
ENFOQUE SUBGRUPO 4.1

As abordagens da indexação automática que estudam a aplicação operacional da estrutura de projetos

\begin{tabular}{|c|c|c|c|}
\hline DATA & TÍT ULO & AUTOR & INSTITUIÇÃ O \\
\hline 1974 & $\begin{array}{l}\text { U ma linguagem de busca } \\
\text { para sistemas de } \\
\text { recuperação da informação }\end{array}$ & $\begin{array}{l}\text { Iberê L. R. } \\
\text { Teixeira }\end{array}$ & Inpe/SP \\
\hline 1983 & $\begin{array}{l}\text { Indexação automática } \\
\text { baseadas em métodos } \\
\text { lingüísticos e estatísticos } \\
\text { e sua aplicabilidade à } \\
\text { língua portuguesa }\end{array}$ & $\begin{array}{l}\text { A lexandre } \\
\text { A ndreewski } \\
\text { e V itoriano } \\
\text { Ruas }\end{array}$ & $\mathrm{PUC/RJ}$ \\
\hline 1989 & $\begin{array}{l}\text { A valiação da eficiência } \\
\text { da recuperação do } \\
\text { sistema de indexação } \\
\text { Precis }\end{array}$ & $\begin{array}{l}\text { M ariangela } \\
\text { S. L. Fugita }\end{array}$ & $\begin{array}{l}\text { Universidade } \\
\text { Estadual } \\
\text { Paulista }\end{array}$ \\
\hline 1991 & $\begin{array}{l}\text { Indexação automática de } \\
\text { textos: uma abordagem } \\
\text { otimizada e simples }\end{array}$ & $\begin{array}{l}\text { Jaime } \\
\text { Robredo }\end{array}$ & IBICT /Brasília \\
\hline
\end{tabular}

O s artigos inseridos neste subgrupo priorizam a análise dos sistemas automatizados no que tange aos aspectos metodológicos, estruturais e conceituais, bem como a sua aplicação e funcionamento. É comum, entre os estudiosos desta área, a divulgação dos métodos de testagem e operacionalidade destes sistemas, abordando 0 desempenho das funções de processamento, armazenamento e recuperação da informação, como meio de dar-Ihes legitimação. $\mathrm{N}$ a relação com a lingüística, os autores dos artigos se utilizam da abordagem semântica e gramatical como suporte de análise desses sistemas de indexação, porém cada um expõe uma temática diferente na medida em que enfocam os principais sistemas, como 0 Sírius, o Spirit, o Precis e o A utomindex. 0 Sírius é um método de recuperação da informação por meio de linguagens de busca, utilizando palavras-chave com comandos sintáticos e semânticos. 0 Spirit é um sistema francês que é apresentado como proposta de adaptação para língua portuguesa, com uso da ferramenta da lingüística e da estatística, para recuperar a informação filtrada, sem ambigüidades. 0 Precis é um sistema de indexação alfabética de assuntos, com metodologia e vocabulário próprio, dotado de sintaxe e semântica especialmente criados para a indexação. 0 A utomindex é um sistema de indexação que se baseia na identificação de palavras ou expressões significativas por eliminação de palavras vazias, através de processos de análise léxica, sintática e semântica dos textos. Estes artigos avaliam 0 funcionamento destes sistemas objetivando trazer esclarecimentos de como a indexação interfere - positiva ou negativamente - , auxilia ou causa ruído no sistema, diante da formulação de solicitação do usuário, e como, de que maneira, a informação poderá ser apresentada nas bases de dados. A recuperação da informação é hoje um dos grandes desafios da ciência da informação. A fragmentação do conhecimento trouxe para a indexação o desafio constante de se adaptar às novas formas de gerenciar a massa gigantesca de dados acumuladosnas bases de dados. 0 uso de palavras-chave é fundamental para esta recuperação, e a lingüística entra como processo natural na recuperação dessa informação, resolvendo problemas de representação de termos no sistema utilizado pelos usuários. Robredo explica este fenômeno no texto a seguir:

"À medida que o volume dos documentos a processar e a ordenar aumenta além de um certo ponto crítico, não é mais possível contentar-se com a organização dos documentos por grandes classes, pois o usuário exige informações muito mais precisas na representação do conteúdo dos documentos, para poder chegar o mais rapidamente possível a aqueles - e só aqueles - que Ihe interessam" 14.

\section{ENFOQUE SUBGRUPO 4.2}

\section{A recuperação automática e o processamento eletrônico da informação em base de dados}

\begin{tabular}{|c|c|c|c|}
\hline DATA & TÍT ULO & AUTOR & INSTITUIÇÃ O \\
\hline 1986 & $\begin{array}{l}\text { A informática lingüística e } \\
\text { o futuro do português: } \\
\text { elementos de uma definição } \\
\text { para uma política nacional } \\
\text { em Portugal }\end{array}$ & Rogéria Cruz & $\begin{array}{l}\text { União Latina } \\
\text { Paris-França }\end{array}$ \\
\hline 1988 & $\begin{array}{l}\text { A spectos relevantes no } \\
\text { projeto de linguagens para } \\
\text { acesso de base de dados } \\
\text { bibliográficas }\end{array}$ & $\begin{array}{l}\text { Carlos } \\
\text { A lberto M. } \\
\text { H ernandes }\end{array}$ & IBICT/Brasília \\
\hline 1991 & $\begin{array}{l}\text { Representação de conteúdo } \\
\text { via indexação automática } \\
\text { de textos integrais em } \\
\text { língua portuguesa }\end{array}$ & $\begin{array}{l}\text { Flavia } \\
\text { Pereira } \\
\text { B. Manfrim }\end{array}$ & $P \cup C / R J$ \\
\hline 1992 & $\begin{array}{l}\text { Sistemas de informação } \\
\text { em linguagem natural: } \\
\text { em busca de uma } \\
\text { indexação automática }\end{array}$ & $\begin{array}{l}\text { M arcilio } \\
\text { de Brito }\end{array}$ & $\mathrm{IBICT}$ \\
\hline
\end{tabular}

${ }^{14}$ RO BRED O, op. cit., p. 201, nota 13. 
Este subgrupo aborda a análise dos níveis de aplicação da informática no contexto da informação automatizada, tendo como princípio comum a recuperação da informação. C ruzapresenta e defen de, em seu artigo, o desenvolvimento de uma política voltada para a informática lingüística, com o fim de estabelecer uma cooperação visando ao enriquecimento do vocabulário científico e técnico nacional dos países de língua portuguesa. A autora expõe elementos que definirão as estratégias de defesa da língua portuguesa e da cultura nacional, como meio de resistência aos produtos estrangeiros no que tange à aceitação da linguagem desses produtos. Já M amfrim \& Brito abordam a questão do tratamento automático daslinguagens naturais, com análise da gramática empregada no texto. M amfrim destaca três pontos: a problemática da representação e recuperação da informação via computador, a ausência de uma filosofia política para a indexação e a possibilidade de uma recuperação automática de texto integral em língua portuguesa, com aplicações da semântica nas palavras representadas no texto. Os artigos apresentam a normalização do termo em língua portuguesa, no entanto cada um aborda um ângulo do problema.

\section{ENFOQUE SUBGRUPO 4.3}

\section{0 uso do sintagma nominal no encadeamento da informação}

\begin{tabular}{llll}
\hline DATA & TÍTULO & AUTOR & INSTITUIÇÃ O \\
\hline 1996 & $\begin{array}{lll}\text { Uma abordagem } \\
\text { alternativa para o }\end{array}$ & Hélio & IBICT/Brasília \\
& $\begin{array}{l}\text { Kutamento e a } \\
\text { recuperação da informação } \\
\text { textual: os sintagmas }\end{array}$ & \\
& nominais & &
\end{tabular}

Ú nico sobre o tema em toda a pesquisa, este artigo traz uma abordagem alternativa para o uso do sintagma nominal como estruturação do encadeamento do texto, visando ao tratamento e a uma recuperação eficaz da informação em bases de dados. N este artigo, o sintagma nominal serve como acesso ao documento informatizado. D estacando os elementosnecessários ao uso de um sistema de recuperação de informação, aborda ainda a função dos descritores e o significado isolado ou em conjunto de um mesmo termo. Kuramoto afirma que "não se deve confundir significado com referente. A s palavras passam a ter um valor referencial a partir do momento em que elas passam fazer parte de um universo do discurso"15. A presenta figuras das estruturas de anál ise considerando os níveis de forma absoluta e a relatividade dosseus níveis.

\footnotetext{
${ }^{15} \mathrm{~K}$ URA M O T O , H élio. U ma abordagem alternativa para o tratamento e a recuperação da informação textual : os sintagmas nominais. C iência da Informação, Brasília, v. 25, n. 2, p. 182-192, maio/ago. 1996. p. 183.
}

\section{GRUPO 5: AS RELAÇÕES CURRICULARES}

Os artigos enquadrados neste grupo cinco da pesquisa tratam da formação profissional no contexto lingüístico. Foram selecionados cinco artigos que tratam de maneira ampla a questão da formação do profissional da informação sob diferentes pontos de vista, porém todos engajados na necessidade de maior reflexão desse profissional no seu campo de atuação. A biblioteconomia no Brasil, que teve o seu início nos porões da Biblioteca $\mathrm{N}$ acional, está hoje em um patamar bastante evoluído em relação às questões de ensino, em que se procura adequar os cursos para as necessidades profissionais do mercado, criando outros cursos complementares à formação, tais como os cursos de especialização e de pós-graduação stricto sensu. Como as abordagens dos artigos são idênticas, pois fazem uma reflexão sobre a profissão, examinaremos os cinco artigos dentro de um único subgrupo.

\section{SUBGRUPO}

5.1 - A s relações curriculares da lingüística com a biblioteconomia, a documentação e a ciência da informação.

\section{ENFOQUE SUBGRUPO 5.1}

As relações curriculares da lingüística com a biblioteconomia, a documentação e a ciência da informação

\begin{tabular}{|c|c|c|c|}
\hline DATA & TÍTULO & AUTOR & IN STITUIÇÃ O \\
\hline 1977 & $\begin{array}{l}\text { Epistemologia social, } \\
\text { semântica geral e } \\
\text { biblioteconomia }\end{array}$ & Jesse Shera & $\begin{array}{l}\text { CN Pq. } \\
\text { Tradução: } \\
\text { M aria Esther } \\
\text { de A. Coutinho }\end{array}$ \\
\hline 1983 & $\begin{array}{l}\text { Perspectiva na } \\
\text { contribuição da } \\
\text { lingüística e de áreas } \\
\text { afins à ciência da } \\
\text { informação }\end{array}$ & $\begin{array}{l}\text { Ulf } \\
\text { Gregor } \\
\text { Baranow }\end{array}$ & $\begin{array}{l}\text { Universidade } \\
\text { de Brasília }\end{array}$ \\
\hline 1985 & $\begin{array}{l}0 \text { ensino de } \\
\text { biblioteconomia no } \\
\text { Brasil }\end{array}$ & $\begin{array}{l}\text { Suzana P. M. } \\
\text { M ueller }\end{array}$ & $\begin{array}{l}\text { Universidade } \\
\text { de Brasília }\end{array}$ \\
\hline 1995 & $\begin{array}{l}\text { A lguns componentes } \\
\text { lingüísticos no ensino } \\
\text { de terminologia }\end{array}$ & $\begin{array}{l}\text { Jean-Claude } \\
\text { Boulanger }\end{array}$ & $\begin{array}{l}\text { Universidade de } \\
\text { Q ueval Q uebec }\end{array}$ \\
\hline 1997 & $\begin{array}{l}\text { Biblioteconomia: } \\
\text { produção e administração } \\
\text { da interpretação }\end{array}$ & $\begin{array}{l}\text { Clarinda } \\
\text { Rodrigues }\end{array}$ & Unicamp \\
\hline
\end{tabular}


São abordados e apontados diferentes pontos de vista da formação profissional, com destaques para a parte intelectual e reflexiva deste profissional. M ueller examina o conteúdo histórico da formação, Shera destaca o seu caráter social, Baranow e Boulanger abordam a formação do especialista e cientista da informação, e Lucas questiona a intelectualidade do bibliotecário. A grande preocupação do bibliotecário, do cientista da informação ou especialista da informação é tornar acessível a informação produzida mediante a democratização do conhecimento humano. Tratar e transmitir informação implica e requer conhecimento não só da área biblioteconomica, mas também conhecimento de lingüística, pois a interdependência do conhecimento trouxe complexidade à informação, e, para que ela seja transmitida e entendida dentro do contexto do usuário, énecessária uma estrutura semântica adequada. Shera, em artigo social e filosófico, aborda a interdependência e a fragmentação do conhecimento, demonstrando preocupação com o registro e posterior recuperação deste conhecimento. D estaca e enaltece a figura do bibliotecário como agente principal neste processo de socialização da informação, reunindo áreas de fundamental importância, como a epistemologia e a semântica. Baranow destaca a contribuição da lingüística na área da informação e a sua importância na formação de profissionais que irão atuar neste campo, principalmente os terminólogos. Ressalta as novas disciplinas que necessitam de apoio lingüístico para se estabelecerem como teoria e enfatiza os aspectos da lingüística relevantes para a ciência da informação. M ueller faz mais uma retomada do contexto histórico da biblioteconomia no Brasil, na qual traça um perfil deste ensino abordando questões curriculares e a reformulação dos programas de ensino. Este último artigo é importante pelas análises curriculares e profissionais apresentadas, dando uma idéia da evolução da formação profissional nestes últimos 15 anos. Também de teor curricular, Boulanger reafirma a necessidade de maior conhecimento lingüístico para o profissional da informação. Boulanger diz: "A terminologia está situada na junção de diversas disciplinas das ciências da linguagem" ${ }^{16}$. Estas disciplinas inerentes à área da Lingüística são atualmente as mais discutidas no âmbito da ciência da informação. Lucas, por sua vez, coloca dois pontos: a análise do discurso pela prática bibliotecária e a leitura de textos como prática simbólica inserida no conjunto de práticas profissionaise sociais. Discorre sobre os métodos e tratamento da informação através da leitura, com o fim de torná-la acessível pela gestão do conhecimento, representada na capacidade de leitura, análise e interpretação do profissional da informação.

\section{GRUPO 6: AS TECNOLOGIAS DOS SISTEMAS ESPECIALISTASE A INTELIGÊNCIA ARTIFICIAL}

$0 \mathrm{~s}$ artigos enquadrados neste grupo seis da pesquisa abordam o processamento e o tratamento automático da informação por sistemas especial istas. Foram selecionados neste grupo quatro artigos que discutem a estrutura, os modelos e usos operacionais dos sistemas especialistas, que atuam como provedores de informação e agentes na interação com o usuário, gerenciando massas de informações. A função e o objetivo dos sistemas especialistas é tornar mais ágil e dinâmico o processo de uso e recuperação da informação, ou seja, facilitar a interface homem/máquina.

Pautado neste raciocínio, os sistemas especialistas, dentro do contexto da inteligência artificial, apresentam o componente lingüístico e semântico como fator de comunicação auxiliar. 0 s quatro artigos têm em comum vários pontos: a preocupação da recuperação da informação pelo usuário; a comunicação entre especialista, usuário e máquina; a disponibilidade de várias leituras de um mesmo texto e a eficácia dos sistemas especialistas. Como todos os artigos abordam o processamento de recuperação da informação no sistema, analisaram-se todos os artigos em um só subgrupo. 


\section{SUBGRUPO}

\subsection{O s sistemas especialistas e a temática da inteligência artificial para uso na recuperação da informação.}

\section{ENFOQUE SUBGRUPO 6.1}

Os sistemas especialistas e a temática da inteligência artificial para uso na recuperação da informação

\begin{tabular}{|c|c|c|c|}
\hline DATA & TÍTulo & AUTOR & INSTITUIÇÃ O \\
\hline 1982 & $\begin{array}{l}\text { A informática e a } \\
\text { evolução dos centros de } \\
\text { informação a serviço de } \\
\text { mudanças culturais }\end{array}$ & $\begin{array}{l}\text { Marisa B. } \\
\text { Cassim }\end{array}$ & IBICT /Brasília \\
\hline 1995 & $\begin{array}{l}\text { D elineamento às } \\
\text { limitações: sistemas } \\
\text { especialistas e } \\
\text { conhecimento tácito }\end{array}$ & $\begin{array}{l}\text { A riadne } \\
\text { Chloé } \\
\text { Furnival }\end{array}$ & $\begin{array}{l}\text { Universidade } \\
\text { Federal } \\
\text { São Carlos }\end{array}$ \\
\hline 1996 & $\begin{array}{l}\text { Base de dados: a metáfora } \\
\text { da memória científica }\end{array}$ & $\begin{array}{l}\text { Luis } \\
\text { Fernando } \\
\text { Sayão }\end{array}$ & Unirio \\
\hline 1997 & $\begin{array}{l}\text { Inteligência artificial: } \\
\text { sistemas especialistas } \\
\text { no gerenciamento da } \\
\text { informação }\end{array}$ & $\begin{array}{l}\text { Raquel } \\
\text { Dias } \\
\text { M endes }\end{array}$ & IBICT /Brasília \\
\hline
\end{tabular}

$\mathrm{N}$ estes quatro artigos, o ponto principal é o usuário. Segundo Figueiredo, "estudos de usuários são investigações que se fazem para saber o de que os indivíduos precisam em matéria de informação, ou então, para saber se as necessidades de informação por parte dosusuários de uma biblioteca ou de um centro de informação estão sendo satisfeitas de maneira adequada" ${ }^{17}$. 0 advento do computador no tratamento e processamento da informação alterou as atividades documentárias. $0 \mathrm{~s}$ sistemas especialistas desenvolvidos a partir da inteligência artificial trabalham os processos de comunicação homem/máquina. 0 s sistemas especialistas têm a preocupação de oferecer várias leituras a partir da automatização do texto em linguagem de computador. A introdução do analisador semântico nos sistemas especialistas tem a finalidade de proporcionar uma recuperação eficaz, por meio da facilidade de comunicação. Cassim relata em seu artigo as mudanças culturais, as

${ }^{17}$ FIGUEIREDO, Nice Menezes de. Estudos de uso e usuários da informação. Brasília : IBICT, 1994. 154 p. p.7. vantagens do uso da informática e o ponto de vista do usuário que terá ao seu dispor uma série de informações através de uma nova maneira de gerenciamento do conhecimento. Furnival e M endes abordam os sistemas especialistas como ferramenta para viabilizar a comunicação via inteligência artificial. Já Sayão enfoca a representatividade da linguagem documentária como uma metalinguagem com semântica e sintaxe própria e a recuperação dessa informação.

\section{GRUPO 7: A CLASSIFICAÇÃO DECIMAL UNIVERSAL E A LINGÜÍSTICA}

O sartigosenquadrados neste grupo sete da pesquisa tratam da abordagem, na Classificação D ecimal U niversal (CDU ), da questão da lingüística e da linguagem. Foram selecionados neste grupo apenas dois artigos: o primeiro trata da ausência da lingüística na CDU; 0 segundo, da questão da normalização da linguagem nas tabelas de classificação. A CDU, traduzida, editada e difundida no Brasil pelo Instituto Brasileiro de Informação Ciência e Tecnologia (IBICT), é um esquema de classificação de assuntos em língua portuguesa registrados em qualquer tipo de documento. Derivada originalmente da Classificação Decimal de Dewey (CDD), incorpora as mesmas categorias de divisão, sendo mais representativa e flexível na organização de acervos documentais, permitindo o livre acesso dos usuários ao acervo. A pesar da representatividade do tema em apenas dois artigos, este grupo terá dois subgrupos de análise, haja vista a questão da CDU ser bastante ampla.

\section{SUBGRUPOS}

7.1- 0 atraso no desenvolvimento da CDU em relação ao campo lingüístico.

7.2- $A$ ausência de normalização e o uso da linguagem nas tabelas de classificação.

\section{ENFOQUE SUBGRUPO 7.1}

0 atraso no desenvolvimento da CDU no campo lingüístico

\begin{tabular}{|c|c|c|c|}
\hline DATA & TÍTULO & AUTOR & IN STITUIÇÃ O \\
\hline 1975 & $\begin{array}{l}\text { A semântica e a } \\
\text { Classificação D ecimal } \\
\text { U niversal }\end{array}$ & $\begin{array}{l}\text { A bgail de } 0 \text {. } \\
\text { Carvalho e } \\
\text { M aria Beatriz } \\
\text { P. de Carvalho }\end{array}$ & $\begin{array}{l}\text { UFMG e } \\
\text { IBICT } \\
0\end{array}$ \\
\hline
\end{tabular}


N este subgrupo da pesquisa, abordam-se as questões de atualização do desenvolvimento processado no campo lingüístico, bem como a ausência de acompanhamento da temática de divisão e denominação destes campos. A falta de aprofundamento das questões semânticas compõe 0 conteúdo do artigo, que traz um enfoque de revisão e análise crítica da Classificação Decimal Universal, classe 8. Datado de 1975, o artigo retrata a análise feita pelas autoras $C$ arvalho e $C$ arvalho, no contexto da CDU - edição desenvolvida em língua portuguesa da Classe 8 - publicada neste mesmo ano e atualizada até 1973. A ntes da revisão e análise crítica da C DU , as autoras procederam a uma revisão histórica fundamental da lingüística para embasamento do seu estudo. A semântica como fator principal do texto recebeu uma análise profunda da sua origem e evolução, desde a revolução da ciência das significações causada por M ichel Bréal (1904) e mais tarde por N oam Chomsky (1965), que incluiu a semântica nos estudoslingüísticos. A semântica hoje está alojada nos estudos da psicologia, sociologia e lógica, 0 que gerou três categorias de semântica. A semântica voltada para a psicologia trata de resolver problemas da comunicação cognitiva entre os seres humanos. A voltada para os estudos da lógica trata da questão do signo e do objeto, com a aplicação do significado correto. No campo da sociologia, tenta esclarecer as relações entre a forma e o significado de uma palavra (termo) que interage na comunicação do indivíduo com a sociedade. D entro desse contexto, as autoras ainda colocam três aspectos interdependentes considerados pela semântica: o geral, 0 lógico e o lingüístico. A través de conceitos básicos, as autoras expõem a confusão dos termos e dos significados que variam de acordo com o olhar de cada estudioso da área lingüística. Enfocam a chegada da análise semântica à terminologia, ao estudo dos signos, às representações, aos símbolos e finalmente às referências documentais. A presentam as análises, as versões diversas e as divergências terminológicas entrando no campo propriamente dito da CDU, em que constatam a ausência de influência das teorias lingüísticas. A lertam para a aplicação inadequada dos termos lingüística, filologia, literatura, ou seja, a junção destes no assunto, como também a ausência da semântica na divisão hierárquica superior e a sua subordinação à gramática. A nalisam a questão semântica/CDU pela definição da mesma e pela gramática gerativa moderna (1973), concluindo que não houve evolução da lingüística dentro da estrutura da CDU . D entro do contexto deste subgrupo, surgiu a necessidade de se verificar a atualização e evolução ocorrida na CDU nas duas últimas décadas, no que se refere ao campo da lingüística (A N EXO 3).
ENFOQUE SUBGRUPO 7.2

\section{A ausência de normalização e o uso da linguagem nas tabelas de classificação}

\begin{tabular}{llll}
\hline DATA & TÍTULO & AUTOR & IN ST ITUIÇÃ O \\
\hline \multirow{2}{*}{1987} & $\begin{array}{l}\text { Documentação } \\
\text { africanista: linguagem }\end{array}$ & $\begin{array}{l}\text { Isabel Maria } \\
\text { R. Ferin }\end{array}$ & S niversidade de \\
& e ideologia & Cunha & \\
& &
\end{tabular}

V oltado para o campo histórico eideológico, C unha coloca a questão da documentação africanista, em que denuncia a ausência de uso de uma linguagem adequada para 0 registro e a classificação desses documentos. R elata a dispersão e as dificuldades de recuperação dessas informações, visto que os termos utilizados, quando encontrados em tabelas de classificação, são de teor ideológico. Segundo a autora, as classificações relegam a Á frica e seus assuntos afins, porque não existem conceitos que a representem no âmbito de história, geografia, língua, cultura e economia neste instrumento do con hecimento humano. Reclama por uma linguagem própria, estruturada, como vocabulários controlados e tesauros elaborados por equipes compostas de bibliotecários/ documentalistas e especialistas de Á frica em diferentes áreas, como a antropologia, a sociologia, a lingüística e a economia. Conclui que, somente com uma linguagem estruturada reunindo o consenso dos países de língua portuguesa, poder-se-á chegar à obtenção de um instrumento capaz de transferir o produto informação desvinculado da ideologia dessa documentação.

\section{CONCLUSÃO E SUGESTÃ O FINAL}

$\mathrm{N}$ a linha de estudos adotada por esta pesquisa, apresentaram-se várias alternativas de análise, pela própria complexidade do assunto documentação. 0 ptouse, na conclusão final, pela análise em três grandes grupos. Como foi dito antes, a documentação se caracteriza pelo todo e pela parte. Este questionamento surge a partir do momento em que se sai do âmbito da ciência da informação e se insere no contexto da lingüística, que tem o poder de englobar tudo dentro do fator linguagem. Exercitaramse, nesta pesquisa, várias formas de linguagem: Iinguagem documentária, linguagem do conhecimento, linguagem de indexação, linguagem tecnológica, linguagem de sistemas, linguagem curricular, linguagem bibliométrica, linguagem normativa, linguagem artificial, linguagem natural, linguagem teórica, linguagem cognitiva, linguagem do pensamento, linguagem terminológica, linguagem intelectual. 0 essencial de todas estas 
linguagens não são as suas partes, mas sim o todo, que é a linguagem, que torna as partes dependentes de um princípio de análise, pois a linguagem é o próprio objeto do conhecimento.

Em toda a pesquisa, pôde-se constatar a dependência da ciência da informação representada pela gama de problemasinformacionais que buscam soluções no campo da lingüística. A través da análise dosgrupos apresentados, pode-se concluir que conhecimento, informação e representação envolve uma série de atividades e processos de conceitualização e operacionalização, ou seja, produção, tratamento, processamento e disseminação.

O sartigosque serviram de base para este estudo mostraram que 0 acesso à informação, a análise de conteúdo, a estruturação de conceitos, a representação e a geração de novos conhecimentos implicam uma série de linguagens que são dependentes entre si, pelas suas partes, como confirma H jelmslev, quando diz que a totalidade não se compõe de objetos, mas de dependências ${ }^{18}$. Este fato explica o relacionamento, a interface imposta pela evolução do conhecimento à lingüística e à ciência da informação presente em todos os campos abrangidos pela pesquisa, como veremos a seguir.

A abordagem temática dos artigos caracterizou-se pela generalização dos problemas informacionais, nos quais se busca entender os mecanismos mentais, os níveis de complexidade e as metodologias aplicadas à estruturação de conceitos, que são a base fundamental das linguagens científicas e que dependem de uma formulação lingüística para mediar o seu conhecimento teórico. A s abordagens bibliométricas, indexatóriase tecnológicas demonstraram afinidades ímpares pelo seu grau de dependência das linguagens, pois uma interfere na concepção da outra. A s abordagens classificatórias, que organizam o registro do conhecimento através das normas bibliográficas, estão diretamente ligadas à linguagem do conhecimento. Estas questões são de fundamental importância, se voltadas para o campo de construção teórica da ciência da informação, que está situada entre o tecnológico e o humano, pois atualmente os avanços tecnológicos afetam o conceito e o uso da informação, que por sua vez afetam a própria estruturação do conhecimento.

${ }^{18}$ HJELM SLEV , L ouis. Prolegômenos a uma teoria da linguagem. São Paulo: Perspectiva, 1961. 147 p. p. 28.
A lguns teóricos da área da informação não reconhecem esta dependência, e isto se deve ao fato de a ciência da informação ser uma ciência relativamente nova e imatura, à qual falta consenso, segundo o modelo de evolução da ciência formulado por Kuhn ${ }^{19}$. A ciência da informação procura absorver e ocupar o espaço vazio deixado pela biblioteconomia, que, segundo M ostafa, recusou maiores aprofundamentos teóricos no campo da lingüística como base para entender as normas documentárias.

0 fato de tratar e transmitir conhecimento coloca na ciência da informação, e só nela, a responsabilidade de aprofundamento no campo das ciências humanas e das ciências sociais, e este processo não se fará sem uma abordagem lingüística própria, pois a informação hoje adquiriu caráter estratégico, tornando-se um elemento de influência e poder em toda a esfera do conhecimento humano. Q uem se ocupar de como, quando, onde, por que a informação surge e quem a produz e qual o seu fluxo e destino final também deverá se ocupar da linguagem das linguagens como meio de viabilizar o seu objeto de estudo, e esta é a tarefa da ciência da informação. Se a lingüística atualmente desenvolve, no seu contexto pragmático, áreas essencialmente aplicativas, como a terminologia, a tradutologia, a linguagem computacional, a sociolingüística, a socioterminologia, a textologia, a lingüística matemática entre outras, citadas por Baranow em seu artigo, também a ciência da informação deverá desenvolver estudos aplicativos para estruturar e fundamentar a sua teoria. É no ato de conhecer (linguagem) e de representar (conteúdo) que a ciência da informação definirá o seu objeto de estudo - a informação - , e esta informação não pode ser formulada sem uma linguagem dependende, porém própria. A ciência da informação não deve esperar soluções prontas provenientes da lingüística, pois esta está redimensionando o seu campo teórico, escolhendo universos de pesquisa mais limitados e desenvolvendo novas perspectivas com o objetivo de explicar o seu fenômeno.

A pesar de pouca literatura produzida a respeito desta interseção e apesar da dispersão constatada ao longo dessas três décadas, este é o caminho, pois os estudos e pesquisas efetivados e o debate fazem parte da construção do arcabouço teórico, conferindo validade ao conhecimento produzido. Teóricos como Dahlberg, que desenvolve a Teoria do Conceito, e W üster, autor da T eoria da

${ }^{19} \mathrm{KUHN}$ apud EUGÊNIO, Marconi. A ciência da informação sob a ótica paradigmática de T homas Kuhn : elementos de reflexão. Perspectiva em ciência da informação. Belo H orizonte, v. 1, n. 1, p. 27-39, jan./jun. 1996. p.34. 
Terminologia, procuram soluções para os problemas sistemáticos de construção e representação do conhecimento. Baranow, Boulanger e Faulstich, ligados à terminologia e à socioterminologia, enfatizam, em seus artigos, que esta dependência por parte da ciência da informação só será resolvida quando se fizer um estudo no universo da lingüística e áreas afins e integrá-lo ao programa de formação acadêmica dos futuros cientistas da informação e, a partir daí, formalizar uma linguagem própria que trará subsídios para o desenvolvimento da área da ciência da informação. Kobashi, em artigo recente sobre as interfaces documentárias, analisa todos os campos, áreas, processos e procedimentos da documentação no intuito de sistematizar a interface lingüística e ciência da informação e buscar unificação teórica para o campo da informação ${ }^{20}$. Coloca a importância da crítica sobre os conhecimentos já instalados para que se possa a partir desse ponto propor novos caminhos. A nova tendência apontada por K obashi éa interseção terminologia eanálise documentária; a primeira pertencente ao campo da lingüística, e a segunda, ao campo comutador da biblioteconomia, da documentação e da ciência da informação. São essas duas subáreas que buscarão rigor para as práticas de construção de vocabuláriospara fins de documentação nos próximosanos. N este contexto, temos poucas linhas de pesquisa relacionadas à organização do conhecimento e à recuperação da informação sendo desenvolvidas no país.

A capacidade de exercitar e transitar por diversostipos de linguagem sem esquecer as suas bases teóricas é a meta da ciência da informação, pois a representação ea recuperação da informação estão inseridas em todas as áreas do conhecimento humano. É necessário que os órgãos de ensino e pesquisa se integrem na tarefa de viabilizar cursos de formação de profissionais especializados para fomentar cada vez mais esses estudos e processar novos conhecimentos que trarão fundamentação teórica, disciplinar e científica à ciência da informação. Faulstich coloca em seu artigo que a formação de pessoal especial izado depende da autonomia da terminologia, ou seja, que ela seja inserida nos cursos de graduação e de pósgraduação.
0 objetivo deste trabalho, a partir do levantamento dessa pesquisa, que teve origem em sala de aula devido à ausência de informação a respeito do assunto lingüística e linguagem documentária, é trazer à pauta a necessidade de discussão e reflexão a respeito da formação dos próximos profissionais da informação. Como parte integrante da problemática lingüística e ciência da informação, colocamos aqui a sugestão de que seja implantada, nas universidades brasileiras, no âmbito da graduação e da pós-graduação em biblioteconomia e documentação, a disciplina terminologia, com a finalidade de preparar melhor esses profissionais que atuarão na área de organização do conhecimento e a recuperação da informação, uma vez que a indústria das línguas e o mercado tecnológico dominam a área da informação. A linguagem atualmente assume grande importância diante do poder tecnológico, e a língua é o principal patrimônio, que tem na terminologia um instrumento de política lingüística. Toda esta questão visa a formar profissionais competentes com múltiplas possibilidades de atuação, que poderão desenvolver as suas atividades em qualquer área do conhecimento humano.

A rtigo aceito para publicação em 24-10-2000

\section{REFERÊNCIAS BIBLIOGRÁFICAS}

1. FO U CA ULT, M ichel. A s palavras e as coisas. São Paulo : M artins Fontes, 1999. $541 \mathrm{p}$.

2. MOLES, A braham A ntoine. Sociodinâmica da cultura. São Paulo : Perspectiva, 1974. 336 p.

3. DU BO IS, Jean. Dicionário de lingüistica. São Paulo: Cultrix, 1973. $653 \mathrm{p}$.

4. W A N DERLEY, M anoel A dolpho. Linguagem documentária: acesso à informação - aspectos do problema. C iência da Informação, Rio de Janeiro, v. 2, n.2, p. 175-217, 1973

5. D A H LBERG, Ingetraut. T eoria do conceito. Ciência da Informação, Rio de Janeiro, v. 7, n. 2, p. 101-107, 1978.

6. FONSECA, Edson Nery da. Ciência da Informação e prática bibliotecária. C iência da Informação, Brasília, v. 16, n. 2, p. 25-127, jul./dez. 1987.

7. MOST A FA, Solange Puntel. Ciência da informação : uma ciência, uma revista. Ciência da Informação, Brasília, v. 25, n. 3, p. 305-307, set./dez. 1996.

8. FA ULSTICH, Enilde. Socioterminologia : mais que um método de pesquisa, uma disciplina. Ciência da Informação, Brasília, v. 24, n. 3, p. 281-288, set./dez. 1995.

9. FAULSTICH, Enilde. Terminologia : 0 Projeto brasilterm e a formação de recursos humanos. C iência da Informação, Brasília, v. 24, n.3, p. 356-363, set./dez. 1995.

10. PEIXOTO, Ana Sofia B.; OLIVEIRA, Rosa dos A njos. Terminologia do ensino por computador: abordagem socioterminológica. Ciência da Informação, Brasília, v. 24, n. 3, p. 353-355, set./dez. 1995.
${ }^{20}$ KO BA SH I, N air Yumiko. A nálise documentária e representação da informação. Informare: Cadernos de Pós-graduação em Ciência da Informação, Rio de Janeiro, v. 2, n. 2, p. 5-27, jul./dez. 1996. p. 22. 


\section{A lingüística e a ciência da informação: estudos de uma interseção}

11. M A IA, Elza Lima e Silva. Comportamento bibliométrico na língua portuguesa, como veículo de representação da informação. C iência da Informação, Rio de Janeiro, v. 2, n. 2, p. 99-138. 1973.

12. RIBEIRO, Lais A. A plicação dos métodos estatísticos e da teoria da informação e da comunicação na análise lingüística: estudo da linguagem jornalística. Ciência da Informação, Rio de Janeiro, v. 3, n. 2, p.151-154, 1974.

13. N A KA YA M A, H aruka. T radução e adaptação de tesauros. C iência da Informação, Braślia, v. 15, n. 1, p. 5-25, jan./jun. 1986.

14. M EDEIROS, M arisa B. Basilio. T erminologia brasileira em ciência da informação: uma análise. Ciência da Informação, Brasília, v. 15, n. 2, p. 135-142, jul./dez. 1986.

15. A LVES, leda M aria. Empréstimos nas línguas de especialidade : algumas considerações. C iência da Informação, Brasília, v. 24, n. 3, p. 319-321, set./dez. 1995.

16. M IRA NDA, Ligia $M$ aria $C$ afé de. Terminologia de informática em língua portuguesa: uma análise lingüística e terminológica. C iência da Informação, Braślia, v. 18, n. 2, p. 183-190, jul./dez. 1989.

17. CORREIA, M argarita. 0 léxico na economia da língua. Ciência da Informação, Brasília, v. 24, n. 3, p. 299-307, set./dez. 1995.

18. FIGUEIRED O, Laura Maia de. 0 conceito de relevância e suas implicações. C iência da Informação, Rio de Janeiro, v. 6, n. 2, p. 7578, 1977.

19. ROBRED O. Jaime. Documentação de hoje e de amanhã : uma abordagem informatizada da biblioteconomia e dos sistemas de informação. São Paulo: Global, 1994. 400 p.

20. CRUZ, Rogéria. A informática lingüística e o futuro do português: elementos para a definição de uma política nacional em Portugal. C iência da Informação, Brasília, v. 15, n. 1, p. 27-32, jan./jun. 1986.

21. MA MFRIM, Flávia P. Braga. Representação de conteúdo via indexação automática em textos integrais em língua portuguesa. C iência da Informação, Brasília, v. 20, n. 2, p.191-203, jul./dez. 1991.

22. BRIT O, M arcílio de. Sistemas de informação em linguagem natural: em busca de uma indexação automática. C iência da Informação, Brasilia, v. 21, n. 3, p. 223-232, set./dez.1992.

23. KURAMOTO, Hélio. U ma abordagem alternativa para o tratamento e a recuperação da informação textual : os sintagmas nominais. Ciência da Informação, Brasília, v. 25, n. 2, p. 182-192, maio/ago. 1996.

24. M ÜELLER, Suzana P. M achado. 0 ensino de biblioteconomia no Brasil. C iência da Informação, Brasília, v. 14, n. 1 p. 3-15, jan./jun. 1985.

25. SHERA, Jesse. Epistemologia social, semântica geral e biblioteconomia. Ciência da Informação, Rio de Janeiro, v. 6, n. 1, p. 9-12. 1997.
26. BA RA N O W, U If G regor. Perspectivas na contribuição da lingüística e de áreas afins a ciência da informação. Ciência da Informação, Brasília, v. 12, n. 1, p. 23-35, 1983.

27. BO U LA N GER, Jean-Claude. A Iguns componentes lingüísticos no ensino da terminologia. C iência da Informação, Brasília, v. 24, n. 3, p. 313-318, set./dez. 1995.

28. LUCA S, Clarinda Rodrigues. Biblioteconomia: produção e administração da interpretação. C iência da Informação, Braślia, v. 26, n. 1, p. 46-53, jan./abr. 1997.

29. FIGUEIREDO, Nice Menezes de. Estudos de uso e usuários da informação. Brasilia: IBICT, 1994. 154 p.

30. CA SSIM, Marisa B. A informática e a evolução dos centros de informação a serviço de mudanças culturais. C iência da Informação, Brasília, v. 11, n. 1, p. 61-67, 1982.

31. FURNIV A L, A riadne Chloé. D elineando as limitações : sistemas especial istas e conhecimento tácito. C iência da Informação, Brasília, v. 24, n. 22, p. 204-210, maio/ago. 1995.

32. MENDES, Raquel Dias. Inteligência artificial : sistemas especialistas no tratamento da informação. C iência da Informação, Brasília, v. 26, n. 1, p. 39-45, jan./abr. 1997.

33. SA Y Ã O, Luis Fernando. Base de dados; a metáfora da memória científica. C iência da Informação, Braślia, v. 25, n. 3, p. 314-318, set./dez. 1996.

34. CLA SSIFICA ÇÃ O D ecimal U niversal : edição média em língua portuguesa. 2. ed. Brasília : IBICT, 1987. 505 p.

35. CLASSIFICAÇÃO Decimal Universal : edição padrão internacional em língua portuguesa. Brasília : IBICT, 1997. 1006 p.

36. CA RVA LH O, A bigail de O liveira; CA RVA LH O, M aria Beatriz P. de. A semântica e a Classificação D ecimal Universal. Ciência da Informação, Rio de Janeiro, v. 4, n. 2. p. 91-102. 1975

37. CUNHA, Isabel Maria R. Ferin. Documentação africanista : linguagem e ideologia. C iência da Informação, Braślia, v. 16, p. 1, p. 37-40, jan./jun. 1987.

38. HJELM SLEV, Louis. Prolegômenos a uma teoria da linguagem. São Paulo : Perspectiva, 961. $147 \mathrm{p}$.

39. EUGÊNIO, Marconi. Ciência da informação sob a ótica paradigmática de Thomas K uhn : elementos de reflexão. Perspectiva em Ciência da Informação, Belo H orizonte, v.1, n. 1, p. 27-39, jan./ jun. 1996.

40. KO BA SHI, N air Yumiko. A nálise documentária e representação da informação. Informare. Cadernos de Pós-G raduação em C iência da Informação, Rio de Janeiro, v. 2, n. 2, p. 5-27, jul./dez. 1996.

N ota: trabalho monográfico de conclusão do Curso de Especialização em O rganização do Conhecimento para Recuperação da Informação, 2000 - Universidade do Rio de Janeiro. 


\section{ANEXO 1}

\section{RELAÇÃO DE AUTORES E ASSUNTOS DA PESQUISA POR ANO/DÉCADA}

D os 42 artigos pesquisados, apenas dois autores* escreveram mais de um artigo, o que pode demonstrar a descontinuidade de pesquisas relacionadas ao tema. É importante ressaltar que estes dois autores estão diretamente ligados à área da ciência da informação e da terminologia, campos bastante discutidos na interseção no período da pesquisa.

\begin{tabular}{|c|c|c|}
\hline A no/década & A ssunto & A utor \\
\hline 1973 & Bibliometria & Elza Lima e Silva M aia \\
\hline 1973 & Linguagem D ocumentária & M anoel A. W anderley \\
\hline 1974 & Linguagem de Busca & Iberê R. L. T eixeira \\
\hline 1974 & Bibliometria & Lais A . Ribeiro \\
\hline 1975 & Classificação Bibliográfica & A bigail de 0 . Carvalho \\
\hline 1977 & Registro do Conhecimento & Jesse Shera \\
\hline 1977 & O rganização de Conceito & Suman Datta \\
\hline 1977 & Conceito de Relevância & Laura M. de Figueiredo \\
\hline 1978 & T eoria do Conceito & Ingetraut Dahlberg \\
\hline 1982 & Informática & M arisa B. Cassim \\
\hline 1983 & Linguagem D ocumentária & A nna M aria M. Cintra \\
\hline 1983 & Ciência da Informação & U If G regor Baranow \\
\hline 1983 & Indexação A utomática & A lexandre A ndreewsky \\
\hline 1984 & Informação e Conhecimento & M aria N élida G. de Gomez* \\
\hline 1985 & Biblioteconomia & Suzana P. M. M ueller \\
\hline 1986 & Tesauros & $\mathrm{H}$ aruka N akayama \\
\hline 1986 & Processamento Informação & Rogéria Cruz \\
\hline 1986 & Terminologia & M arisa Basilio M edeiros \\
\hline 1987 & N ormalização Bibliográfica & Isabel M.R. Ferin Cunha \\
\hline 1987 & Ciência da Informação & Edson N ery da Fonseca \\
\hline 1988 & Base de Dados & Carlos A. M. Hernandes \\
\hline 1989 & Sistemas de Indexação & M ariângela S. Lopes Fujita \\
\hline 1989 & Terminologia & Ligia $M$ aria $C$. de $M$ iranda \\
\hline 1991 & Indexação A utomática & Jaime Robredo \\
\hline 1991 & Indexação A utomática & Flavia P. Braga M amfrim \\
\hline 1992 & Indexação A utomática & M arcílio D e Brito \\
\hline 1993 & Representação & M aria N élida G. De Gomez* \\
\hline 1993 & Semiologia, Semiótica & M arilda Lopes G. De Lara \\
\hline 1995 & Sistemas Especialistas & A riadne $C$ hloé F urnival \\
\hline 1995 & Socioterminologia & Enilde Faulstich* \\
\hline 1995 & Léxico & M argarita Correia \\
\hline 1995 & Terminologia & Jean-Claude Boulanger \\
\hline 1995 & Empréstimo Lingüístico & Ieda M aria A Ives \\
\hline 1995 & Lexicografias & M aria A parecida Barbosa \\
\hline 1995 & Terminologia & A na Sofia Brito Peixoto \\
\hline 1995 & Terminologia & Enilde Faulstich* \\
\hline 1996 & Sintagmas N ominais & Hélio Kuramoto \\
\hline 1996 & Representação Informação & M aria Luiza A . Campos \\
\hline 1996 & Ciência da Informação & Solange Puntel M ostafa \\
\hline 1996 & Base de Dados & Luis Fernando Sayão \\
\hline 1997 & Inteligência A rtificial & Raquel $D$ ias $M$ endes \\
\hline 1997 & Biblioteconomia & Clarinda R. Lucas \\
\hline
\end{tabular}


A lingüística e a ciência da informação: estudos de uma interseção

\section{ANEXO 2}

O s assuntos mais desenvolvidos e pesquisados pelos autores na interface lingüística e ciência da informação.

\begin{tabular}{|c|c|c|}
\hline & A ssunto & A utor/A rtigo \\
\hline 1 & terminologia & 5 \\
\hline 2 & indexação automática & 4 \\
\hline 3 & ciência da informação & 3 \\
\hline 4 & bibliometria & 2 \\
\hline 5 & biblioteconomia & 2 \\
\hline 6 & linguagem documentária & 2 \\
\hline 7 & base de dados & 2 \\
\hline 8 & sistemas especialistas & 2 \\
\hline 9 & linguagem de busca & 1 \\
\hline 10 & classificação bibliográfica & 1 \\
\hline 11 & registro do conhecimento & 1 \\
\hline 12 & organização de conceitos & 1 \\
\hline 13 & conceito de relevância & 1 \\
\hline 14 & processamento informação & 1 \\
\hline 15 & normalização bibliográfica & 1 \\
\hline 16 & sistemas de indexação & 1 \\
\hline 17 & representação conhecimento & 1 \\
\hline 18 & representação informação & 1 \\
\hline 19 & semiologia, semiótica & 1 \\
\hline 20 & léxico & 1 \\
\hline 21 & empréstimo lingüístico & 1 \\
\hline 22 & lexicografia & 1 \\
\hline 23 & tesauro & 1 \\
\hline 24 & socioterminologia & 1 \\
\hline 25 & informação e conhecimento & 1 \\
\hline 26 & inteligência artificial & 1 \\
\hline 27 & teoria do conceito & 1 \\
\hline 28 & informática & 1 \\
\hline
\end{tabular}




\section{ANEXO 3}

\section{ALTERAÇÕES OCORRIDAS NA CDU NAS DUAS ÚLTIMAS DÉCADAS}

T endo como principal objetivo verificar o grau de interação entre a Lingüística e a Ciência da Informação e sendo o código de Classificação D ecimal U niversal (CDU) um representante formal da estruturação do conhecimento reconhecido e viabilizado pela área da Ciência da Informação e um instrumento de trabalho dos profissionais que lidam com a organização do conhecimento e a recuperação da informação, este estudo, dentro do seu contexto da pesquisa, buscou registrar e disponibilizar as atualizações ocorridas nas duas últimas décadas na CDU . D ada a própria natureza de revisão e atualização constante do Sistema de Classificação (CDU), procurou-se verificar a evolução registrada nas edições em língua portuguesa dos anos de 1987 e de 1997, em que se constata a preocupação deste instrumento com a referida evolução nas áreas da informação e da linguagem. A edição de 1987 ainda traz a Lingüística ligada à Literatura e à Filologia. N 0 sumário, lê-se Linguagem, Lingüística, Literatura. A classe 800/800.958, Q uestões G erais de Lingüística, é dedicada as línguas e linguagens e suas fases de desenvolvimento. A classe 801, Lingüística e Filologia em geral, trata da estrutura da língua, como ortografia, oração, lexicologia, vocabulário, dicionário, fonética, gramática, prosódia. A classe 802 a 809 trata das línguas específicas. A classe 82 é dedicada à literatura em geral. A classe 820 a 899 trata das literaturas de diversas línguas e não está completamente desenvolvida.

A edição de 1997 dedica a classe 80 à Filologia e toda a classe 81 aos estudos de Lingüística e Línguas. A presenta auxiliares especiais para serem usados na classe 81 , para indicar o assunto da Lingüística ou geral e também em combinação com as subdivisões 811 para os aspectos lingüísticos de determinadas línguas ou grupos de língua. A presenta a classe $81^{\prime} 1$ Lingüística Geral, onde podem ser classificados textos sobre Lingüística, bem como documentos que abordem vários assuntos de Lingüística. A classe $81^{\prime} 16$ é dedicada à $M$ etateoria da Lingüística. A classe $81^{\prime} 2$ /' 44 aborda as áreas temáticas e facetas da L ingüística, como a T eoria geral dos signos em relação à Lingüística, Semiologia, Semiótica; a Psicolingüística; a T eoria da T radução; a Sociolingüística; a L ingüística G eográfica. Dialetologia; a Lingüística $M$ atemática, a Lingüística Computacional e Estatística; a Lingüística A plicada; a Fonética, a Fonologia; a O rtografia; a Gramática. M orfologia. Sintaxe; a Semântica. Lexicologia. Lexicografia; a Estatística G ]eral; a A nálise do D iscurso; Lingüística T ipológica. A lgumas dessas subclasses estão bastante desenvolvidas, outras não, inclusive a Semântica. A s línguas de maneira geral são apresentadas nas divisões principais da classe 811. A literatura encontra-se toda na classe 82. Esta versão de 1997, que teve como ponto de partida a edição de 1987 e se apresenta atualizada até 1995, traz melhor distribuição dos assuntos dentro da sua temática própria, sendo um pouco mais en riquecida de termos nas divisões de Língua, Lingüística, Literatura. 0 objetivo deste anexo não foi fazer uma análise apurada dessas duas edições; mesmo porque, este não é o objetivo deste trabalho; mas, sim, fazer constar de maneira superficial, porém embasada, a evolução ocorrida no registro da Lingüística dentro do contexto da CDU. 